\title{
Ambient Light Problem Identified
}

National Cancer Institute

\section{Source}

National Cancer Institute. Ambient Light Problem Identified. NCI Thesaurus. Code

C139491.

Device performance was affected by ambient light. This term applies to the direct effects of ambient light on the device, and to the user's ability to operate the device (e.g. to read device output). 